LBNL-XXXXX

\title{
Customer Impact Evaluation for the 2009 Southern California Edison Participating Load Pilot
}

\author{
Prepared for the \\ Public Interest Energy Research Program \\ California Energy Commission \\ Prepared by \\ William Gifford, Shawn Bodmann, Paul Young, KEMA \\ Joseph H. Eto, Lawrence Berkeley National Laboratory \\ Jeremy Laundergan, Southern California Edison \\ Ernest Orlando Lawrence Berkeley National Laboratory \\ 1 Cyclotron Road, MS 90R4000 \\ Berkeley CA 94720-8136
}

February, 2010

This work described in this paper was funded by the Assistant Secretary of Energy Efficiency and Renewable Energy, Distributed Energy Program of the U.S. Department of Energy under Contract No. DE-AC02-05CH11231. 



\section{Acknowledgments}

The 2009 PLP Customer Impact Evaluation was sponsored by Lawrence Berkeley National Laboratory. This report was produced by LBNL as a co-sponsor in support of the overall Participating Load Pilot (PLP) effort managed by SCE. The LBNL contribution to the PLP included the purchase of the indoor temperature monitors used in this study as well as the analysis of the resulting indoor temperature data and the analysis of the data collected from the household impact surveys.

The 2009 PLP was a coordinated team effort between several organizations, managed by Kevin Wood and led by Jeremy Laundergan of Southern California Edison with Muir Davis, Trey Howard, and Eric Bell supporting on the SCE side. Mark Rupnik, Bill Zollars, Tom Quick, and Vince Frisna of BPL Global collected, presented, and stored the telemetered temperature data that was used in this project and provided secure delivery of the readings on a daily basis to KEMA for analysis. 



\section{Table of Contents}

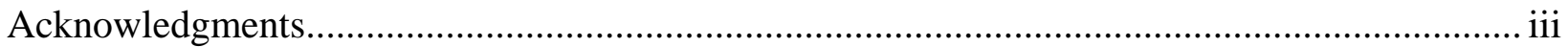

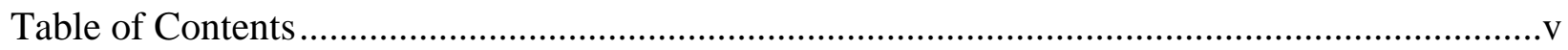

List of Figures and Tables........................................................................................................ vii

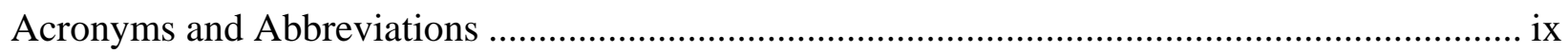

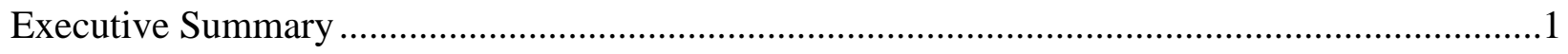

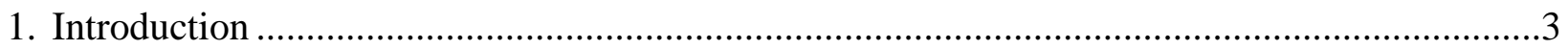

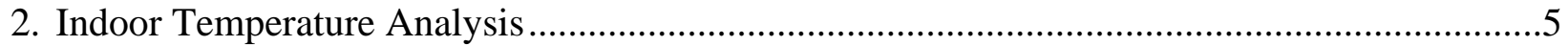

2.1 Indoor Temperature Device Transmission Reliability..........................................................

2.2 Indoor Temperature Changes During 2009 PLP Test Events...............................................

2.3 Regression of Indoor Temperature Increases on Event Duration, Outside Temperature...11

2.4 Logistic Regression of Indoor Temperature Increases on Event Duration, Outside

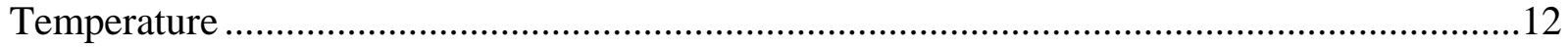

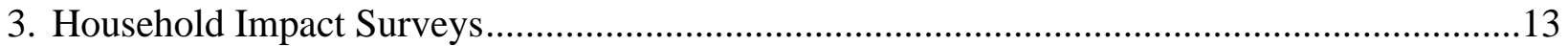

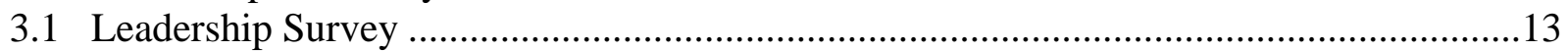

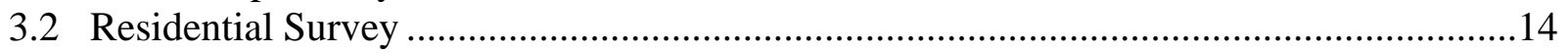

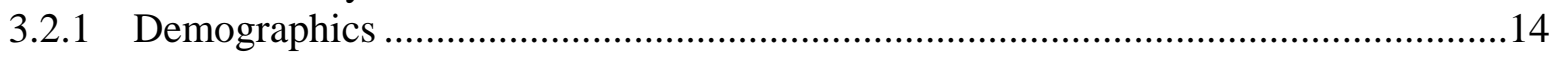

3.2.2 Typical Summer Air Conditioner Use .................................................................15

3.2.3 Awareness of Summer Curtailment Events ................................................................19

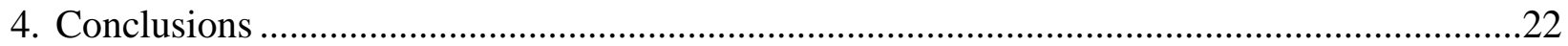





\section{List of Figures and Tables}

\section{Figures:}

Figure 2.1 Temperature readings were collected by BPL Global and transferred to KEMA....... 5

Figure 2.2 Count of Transmitting Devices by Time .............................................................. 6

Figure 2.3 Number of Late Timestamps by the Total Unaccounted For Hours ......................... 7

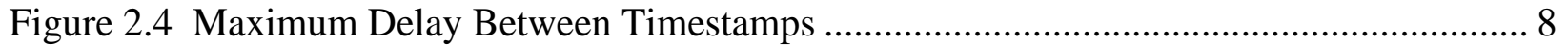

Figure 2.5 Number of Events with Unaccounted-for Temperature .......................................... 8

Figure 2.6 Average Unaccounted for Time from Late Temperature Readings ........................... 9

Figure 2.7 Count of indoor Temperature increases During Events by Event Durations Across All

Events, Monitored Households

Figure 2.8 Count of indoor temperature increases during events by event durations and outside temperature across all events, monitored households ................................................. 10

Figure 2.9 Predicted Indoor Temperature Increase by Actual Temperature Increase (Zero and one degree increases removed).

Figure 2.10 Temperature difference indicator by estimated probability of increase with fitted log of estimated probability. 13

\section{Tables:}

Table 1.1 Event Duration and Outside Temperature Summary............................................. 4

Table 2.1 Indoor Temperature Transmission Date Spans..................................................... 6

Table 2.2 Count of the occurrences of zero and one degree temperature increases removed from

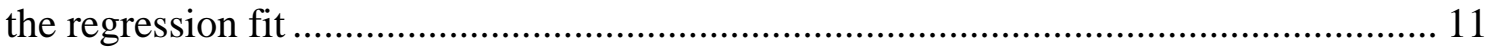

Table 2.3 Regression Parameter Estimates and Associated Levels of Precision......................... 11

Table 2.4 Logistic Regression Parameter Estimates and Associated Levels of Precision........... 13

Table 3.2 Weekdays When Someone Is Home.................................................................. 15

Table 3.3 Air Conditioner Usage ............................................................................... 15

Table 3.4 Thermostat Usage ............................................................................................ 16

Table 3.5 Outside Temperature Inducing Air Conditioning ................................................... 16

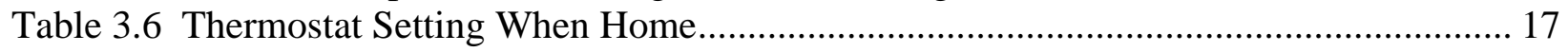

Table 3.7 Thermostat Setting When Gone......................................................................... 18

Table 3.8 Thermostat Setting During Sleeping Hours.......................................................... 19

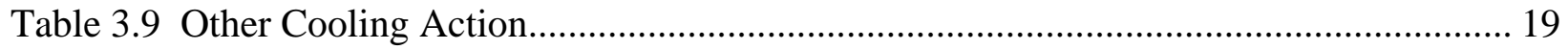

Table 3.10 Performance Differences Versus Last Summer .................................................... 20

Table 3.11 Time When Tests Were Noticed.......................................................................... 20

Table 3.12 How Noticeable Tests Were ................................................................................. 21

Table 3.13 Affect Tests Had On Comfort Level................................................................. 21

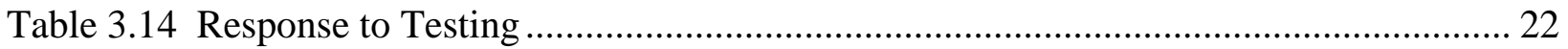





\section{Acronyms and Abbreviations}

$\begin{array}{ll}\text { AC } & \text { Air Conditioning } \\ \text { CAISO } & \text { California Independent System Operator } \\ \text { DR } & \text { Demand Response } \\ \text { DRSP } & \text { Demand Response Spinning Reserve Pilot } \\ \text { LBNL } & \text { Lawrence Berkeley National Laboratory } \\ \text { MRTU } & \text { Market Redesign and Technology Upgrade } \\ \text { PLP } & \text { Participating Load Pilot } \\ \text { SCE } & \text { Southern California Edison } \\ \text { SDP } & \text { Summer Discount Plan }\end{array}$





\section{Executive Summary}

The 2009 Participating Load Pilot Customer Impact Evaluation provides evidence that short duration demand response events which cycle off air conditioners for less than thirty minutes in a hot, dry environment do not lead to a significant degradation in the comfort level of residents participating in the program.

This was investigated using

1) Analysis of interval temperature data collected from inside residences of select program participants; and

2) Direct and indirect customer feedback from surveys designed and implemented by Southern California Edison at the conclusion of the program season.

There were 100 indoor temperature monitors that were acquired by LBNL for this study that transmitted temperature readings at least once per hour with corresponding timestamps during the program season, June - October, 2009. Recorded temperatures were transferred from the onsite telemetry devices to a mesh network, stored, and then delivered to KEMA for analysis. Following an extensive data quality review, temperature increases during each of the thirty demand response test events were calculated for each device. The results are as follows:

1) Even for tests taking place during outside temperatures in excess of 100 degrees Fahrenheit, over 85 percent of the devices measured less than a 0.5 degree Fahrenheit temperature increase indoors during the duration of the event.

2) For the increases that were observed, none was more than 5 degrees and it was extremely rare for increases to be more than 2 degrees.

At the end of the testing season SCE and KEMA designed and conducted a survey of the a facilities and public works managers and approximately 100 customers feedback survey to assess the extent the PLP events were noticed or disrupted the comfort level of participants. While only a small sampling of 3 managers and 16 customer surveys were completed, their responses indicate:

1) No customer reported even a moderate level of discomfort from the cycling-off of their air conditioners during test events.

2) Very few customers noticed any of the thirty events at all.

The results of this study suggest that the impacts on comfort from short-duration interruptions of air-conditioners, even in very hot climates, are for the most part very modest, if they are even noticed at all. Still, we should expect that these impacts will increase with longer interruptions of air-conditioning. By the same token, we should also expect that they will be less significant in cooler climates. 



\section{Introduction}

Following the successful demonstration in the summer of 2008 of how air conditioning load management resources could be used to provide spinning reserve through demand response, Southern California Edison (SCE) modified its Demand Response Spinning Reserve Pilot $\left(\mathrm{DRSRP}^{1}\right)$ to investigate the feasibility of bidding small, aggregated demand response from air conditioning as participating load (PL) according to requirements specified by the California Independent System Operator (CAISO). This 2009 SCE initiative, known as the Participating Load Pilot $^{2}$ (PLP), was launched at the urging by CAISO that some PL be ready at the deployment of Market Redesign and Technology Upgrade (MRTU) Release 1.

SCE partnered with Lawrence Berkeley National Laboratory (LBNL) and KEMA to develop an implementation plan for the PLP. Over 3,200 air conditioning units in both residential and nonresidential buildings on the National Training Center and Fort Irwin military installation in California had already been participating in an A/C cycling switch program through the SCE Summer Discount Plan (SDP), which grants participating customers a credit on their bills in exchange for allowing SCE limited cycling capability the registered A/C units throughout the summer program season. SCE offered a further incentive to the base for allowing it to conduct further tests beyond the SDP to assess PLP events in terms of how well the demand response (DR) could be forecasted and measured after the fact.

A sample of approximately 550 of the air conditioners equipped with the SDP switch had a load monitoring telemetry device installed as part of the PLP. This was a statistically designed sample so that the load readings transmitted from these devices could be used to make precise estimates of the total load for all of the approximately 3,200 A/C units.

Approximately 100 of the residential buildings with the load monitoring telemetry device installed were additionally given plug-in indoor temperature monitoring devices with the same telemetry capability as the load sensors. These devices ${ }^{3}$ were acquired by LBNL for the purpose of determining the impact the five to twenty minute PLP events had on the comfort level of the customers.

Along with the monitoring of indoor temperatures during test events, SCE and KEMA designed and fielded a survey of both PLP participants who had the indoor temperature sensors for their awareness of the PLP tests and facilities and public works management personnel on the base for feedback they may have received from residents. The residential survey sought information

${ }^{1}$ Eto, J., J. Nelson-Hoffman, E. Parker, C. Bernier, P. Young, D. Sheehan, J. Kueck, and B. Kirby. 2009. Demand Response Spinning Reserve Demonstration - Phase 2 Findings from the Summer of 2008. (LBNL-2490E). Available at http://certs.lbl.gov/certs-load-pubs.html 2009 PLP Feasibility Report available at http://www3.sce.com/sscc/law/dis/dbattach3e.nsf/0/8CEDA19110F726598825769B00817D3C/\$ FILE/A.08-06-001+et+al.+-++2009-11+DR+App+-+SCE+PLP+Feasibility+Report.pdf

${ }^{3}$ BPL Global Power SG Temperature Sensor. While these devices have the capability of regulating $\mathrm{A} / \mathrm{C}$ compressors, they were only used for transmitting indoor temperatures. More information at http://www.bplglobal.net/eng/products-services/power-sg-residential-demandmanagement/index.aspx 
relating to the neighborhood, thermostat usage, and comfort perception during the summer of 2009. The building management survey asked for the types of buildings they were responsible for and the number and types of complaints received related to air conditioning in the summer of 2009.

LBNL funded the analysis of the returned surveys in support of having another means of assessing the impact the PLP had on program participants along with the indoor temperature dynamics during events. These components combined to give an insight into the sensitivity people have to air conditioning interruptions of varying levels of durations and at various outside temperatures. Table 1.1 summarizes the event durations and corresponding outside temperatures.

\begin{tabular}{|l|r|r|r|r|r|}
\hline $\begin{array}{l}\text { Outside Temperature } \\
\text { (Degrees Fahrenheit) }\end{array}$ & \multicolumn{4}{|c|}{ Event Duration (Minutes) } & \multicolumn{2}{l|}{ Ten } & \multicolumn{2}{c|}{ Twenty } & \multicolumn{2}{c|}{ Total } \\
\hline$<70$ & 0 & 1 & 1 & 2 \\
\hline $70-79$ & 1 & 3 & 2 & 6 \\
\hline $80-89$ & 3 & 4 & 1 & 8 \\
\hline $90-99$ & 3 & 7 & 2 & 12 \\
\hline $100+$ & 0 & 2 & 0 & 2 \\
\hline Total & 7 & 17 & 6 & 30 \\
\hline
\end{tabular}

Table 1.1 Event Duration and Outside Temperature Summary 


\section{Indoor Temperature Analysis}

The indoor temperatures transmitted from the devices were collected and processed by BPL Global, and then delivered to KEMA in the form of daily files with each recorded temperature for that day along with the device identifier and timestamp for each reading. Figure 2.1 shows the plug-in indoor temperature monitoring device that transmits temperature readings via a wireless mesh network, which were then collected by BPL Global and transferred to KEMA.

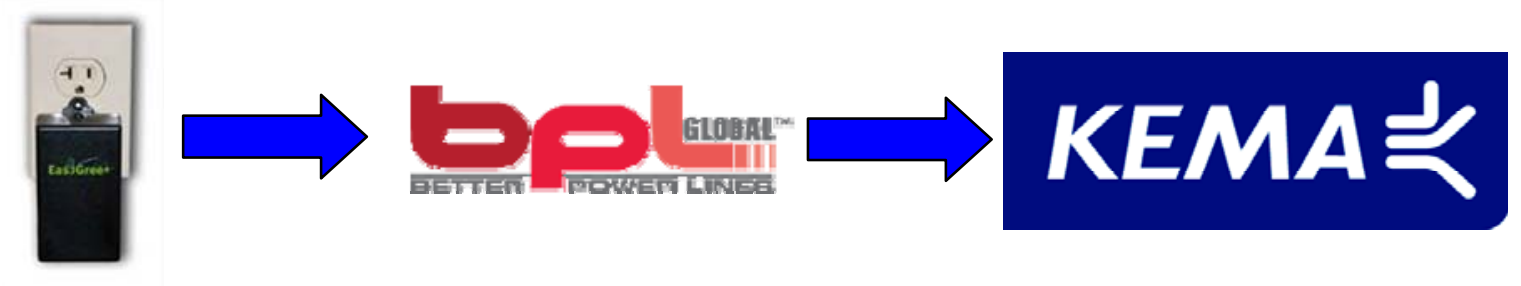

Figure 2.1 Temperature readings were collected by BPL Global and transferred to KEMA.

KEMA approached the indoor temperature analysis by first conducting a thorough inspection of the temperature data quality. The reliable temperatures are then used in calculating the increases in temperature from the start to the end of each of the thirty PLP test events for each device. It should be noted that some devices did not transmit readings for all of the thirty tests. This may be due to a variety of causes including the plug-in nature of the device and a customer possibly unplugging the device in order to utilize the outlet. Fixed-effects regression models were then fit to the temperature increases using event duration and outside temperatures as explanatory variables.

The location of the temperature sensors tended to be 12 to 16 inches off the floor, a typical position for electrical outlets. A single sensor cannot provide a reliable measure of temperature throughout an entire premise and hence no claims are made in this report to that effect. Still, barring extreme placements, recorded changes in temperature should be a reliable indicator of the relative effects of short duration air conditioner interruptions.

\subsection{Indoor Temperature Device Transmission Reliability}

As with the air conditioner load measuring devices, the indoor temperature devices were supposed to produce a reading with the indoor temperature at least once per hour, and more if the temperature changed more than a designated amount. 


\begin{tabular}{|c|c|c|c|c|c|c|c|c|}
\hline & \multicolumn{8}{|c|}{ First Reading Date } \\
\hline Last Reading Date & $6 / 18 / 2009$ & $6 / 26 / 2009$ & $7 / 7 / 2009$ & $8 / 1 / 2009$ & $8 / 10 / 2009$ & $10 / 13 / 2009$ & $10 / 26 / 2009$ & Total \\
\hline $7 / 8 / 2009$ & 1 & & & & & & & 1 \\
\hline $7 / 11 / 2009$ & 1 & & & & & & & 1 \\
\hline $7 / 16 / 2009$ & 1 & & & & & & & 1 \\
\hline $7 / 18 / 2009$ & 1 & & & & & & & 1 \\
\hline $7 / 20 / 2009$ & 1 & & & & & & & 1 \\
\hline $7 / 21 / 2009$ & & 1 & & & & & & 1 \\
\hline $7 / 23 / 2009$ & 1 & & & & & & & 1 \\
\hline $8 / 4 / 2009$ & & & & 1 & & & & 1 \\
\hline $8 / 5 / 2009$ & 1 & & & & & & & 1 \\
\hline $8 / 31 / 2009$ & 1 & & & & & & & 1 \\
\hline $9 / 2 / 2009$ & 1 & & & & & & & 1 \\
\hline 9/4/2009 & 2 & & & & & & & 2 \\
\hline 9/8/2009 & 1 & & & & & & & 1 \\
\hline $9 / 15 / 2009$ & 1 & & & & & & & 1 \\
\hline $9 / 30 / 2009$ & 1 & & & 1 & & & & 2 \\
\hline $10 / 1 / 2009$ & 1 & & & & & & & 1 \\
\hline $10 / 7 / 2009$ & & & 1 & & & & & 1 \\
\hline $10 / 15 / 2009$ & 1 & & & & & & & 1 \\
\hline $10 / 25 / 2009$ & & & & 1 & & & & 1 \\
\hline $10 / 30 / 2009$ & & & & & & & 1 & 1 \\
\hline $10 / 31 / 2009$ & 70 & & & 6 & 1 & 1 & & 78 \\
\hline Total & 86 & 1 & 1 & $\overline{9}$ & 1 & 1 & 1 & 100 \\
\hline
\end{tabular}

Table 2.1 Indoor Temperature Transmission Date Spans

Table 2.1 contains device counts for the dates of first and last readings. The first column of counts shows that 86 of the 100 indoor temperature devices came online on June $18^{\text {th }}$, 2009, the first day of the PLP event season, and 10 of the remaining 14 began transmitting readings in the first ten days of August. The ending date of the 2009 PLP collection season was October $31^{\text {st }}$, and 78 of the 100 devices delivered temperature readings through that date, with the other 22 scattered between early July and late October.

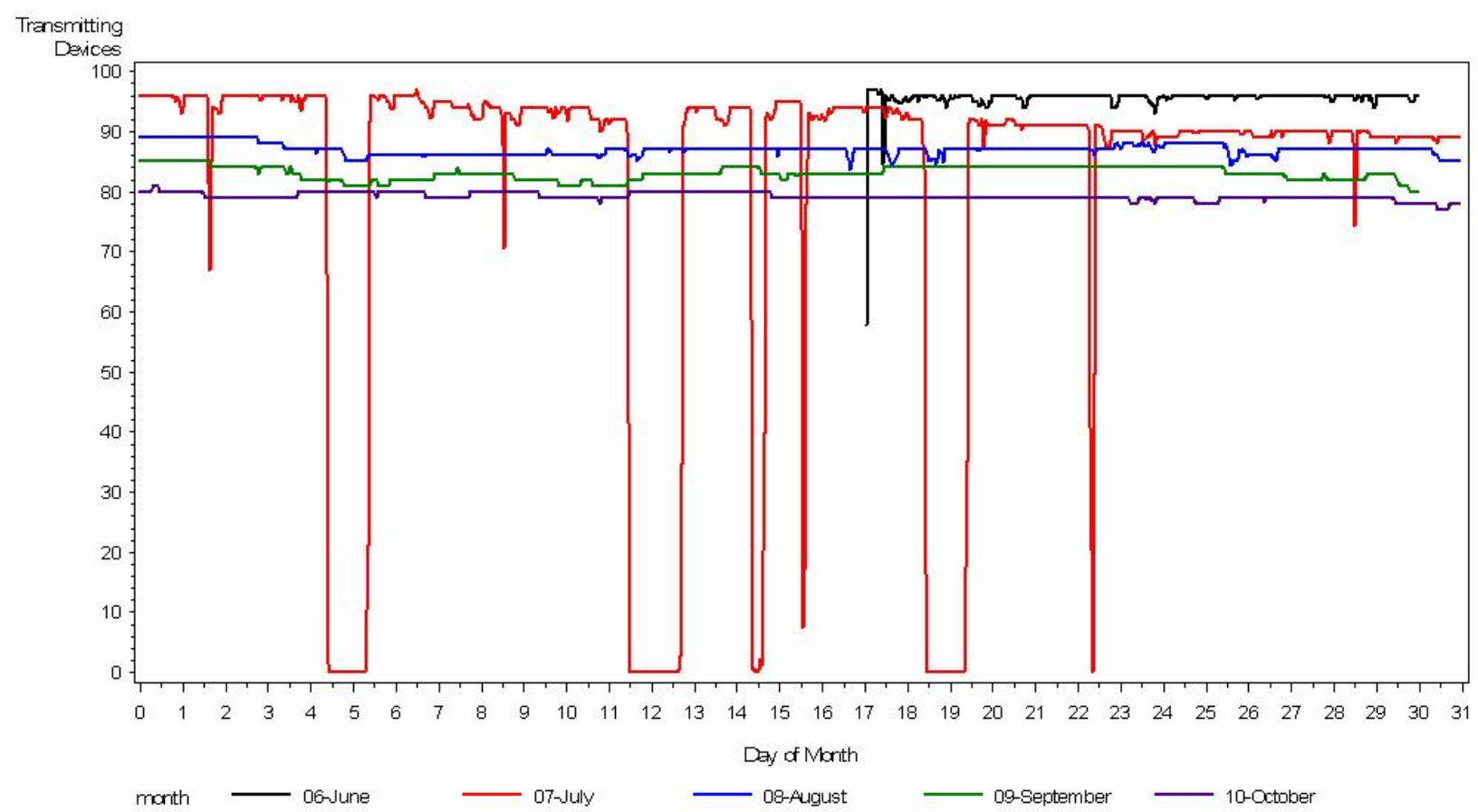

Figure 2.2 Count of Transmitting Devices by Time 
Figure 2.2 gives the number out of the total number out of 100 temperature monitoring devices that are transmitting at the prescribed frequency of one or more readings per hour throughout the event season starting in June and ending in October. Each different colored line represents a different month. July stands out as having several periods with missing data at several points in the month and several downward spikes where significant proportions of the devices failed to transmit a reading every hour. The other months are far more stable than July. Their downward spikes represent fewer than ten simultaneous non-transmitting devices and seem to occur randomly. There is, however, a clear downward trend in the number of transmitting devices throughout the summer as can be seen from the black line representing the June counts above the red line representing July, and so on. Nearly 95 of the 100 temperature devices transmitted reliably in June and by October this was down to about 80.

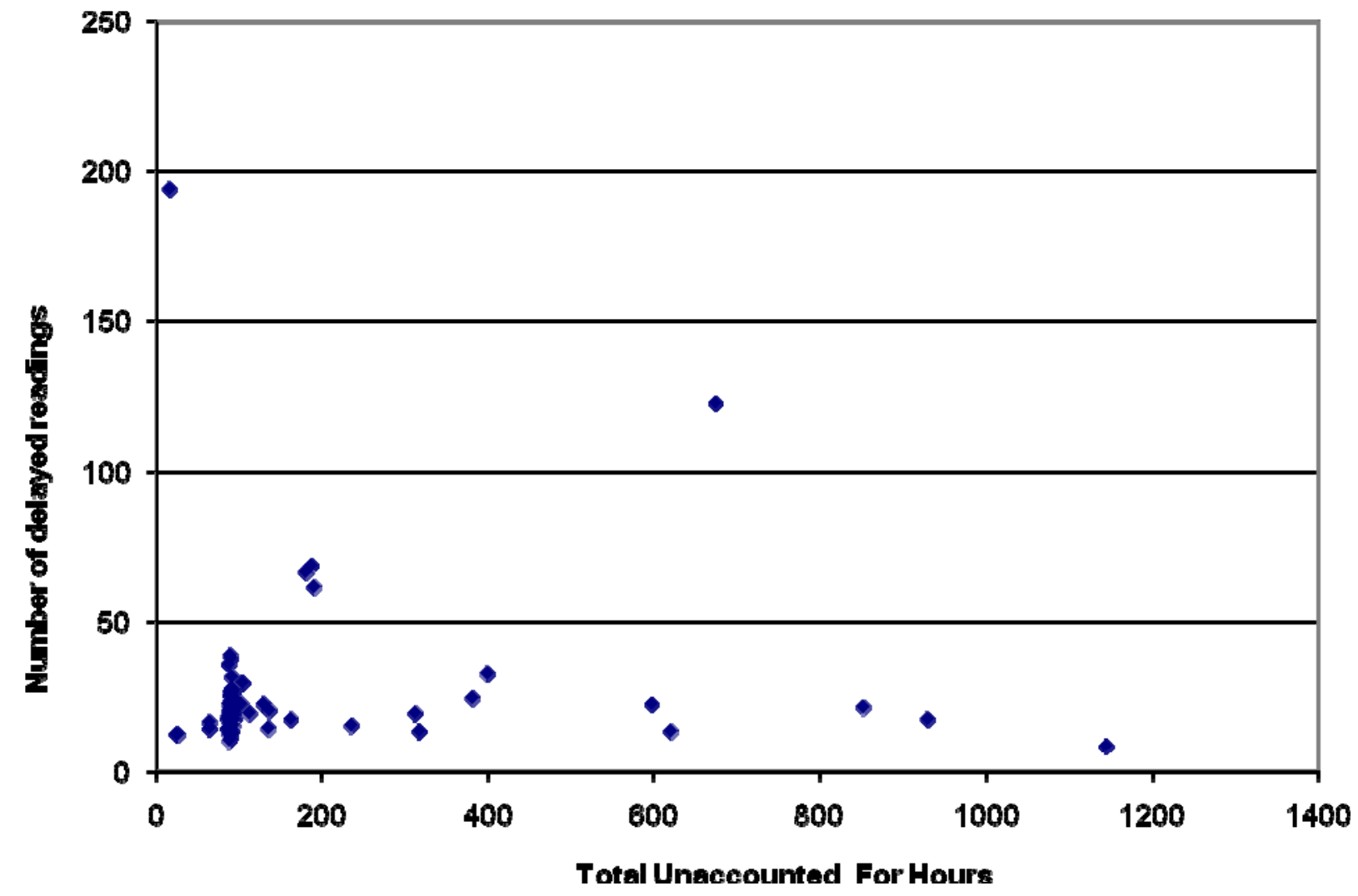

Figure 2.3 Number of Late Timestamps by the Total Unaccounted For Hours

Most devices had between 10 and 40 occurrences of late indoor temperature readings - readings that were transmitted more than an hour after the one prior to it. For most devices, the late readings added up to about 100 hours of unaccounted time, as Figure 2.3 shows. Note that the bulk of these hours are due to the system-wide mass transmission failures in July. 


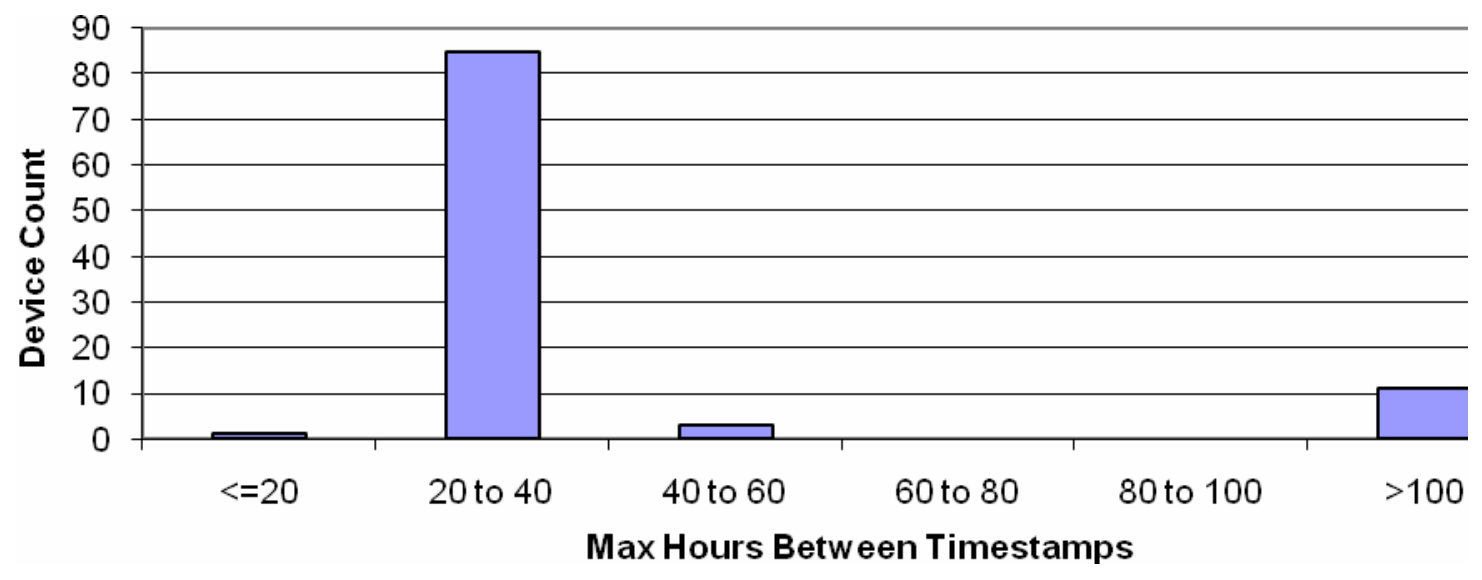

Figure 2.4 Maximum Delay Between Timestamps

The largest time spans between consecutive readings for the temperature monitoring devices are summarized in Figure 2.4. Most devices had a maximum of between 30 and 40 hours between timestamps. Again, these unaccounted for spans of hours generally occurred in the transmission outage periods in July. There were, however, 11 devices that had a span of more than 100 hours between recorded temperature readings. One device had over 1000 hours between readings. Any of these gaps in data may have occurred due to the device being unplugged during the span of unaccounted for hours or other factors which are unknown and out of scope for this analysis.

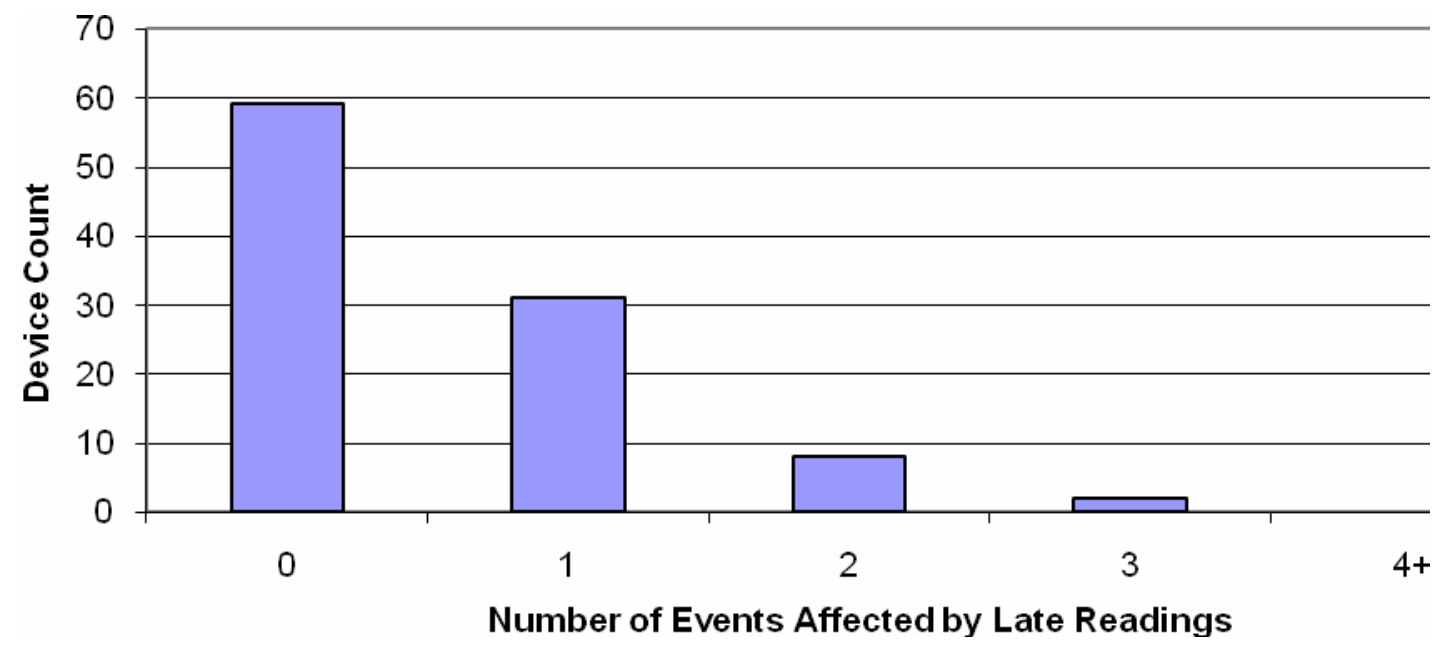

Figure 2.5 Number of Events with Unaccounted-for Temperature

About 40 of the 100 devices had part of a late reading occurring during at least 1 of the 30 test events, as is shown in Figure 2.5. The indoor temperature change could not be measured for these devices on the corresponding events because the temperature at either the start or end of the event (or both) is unknown. 


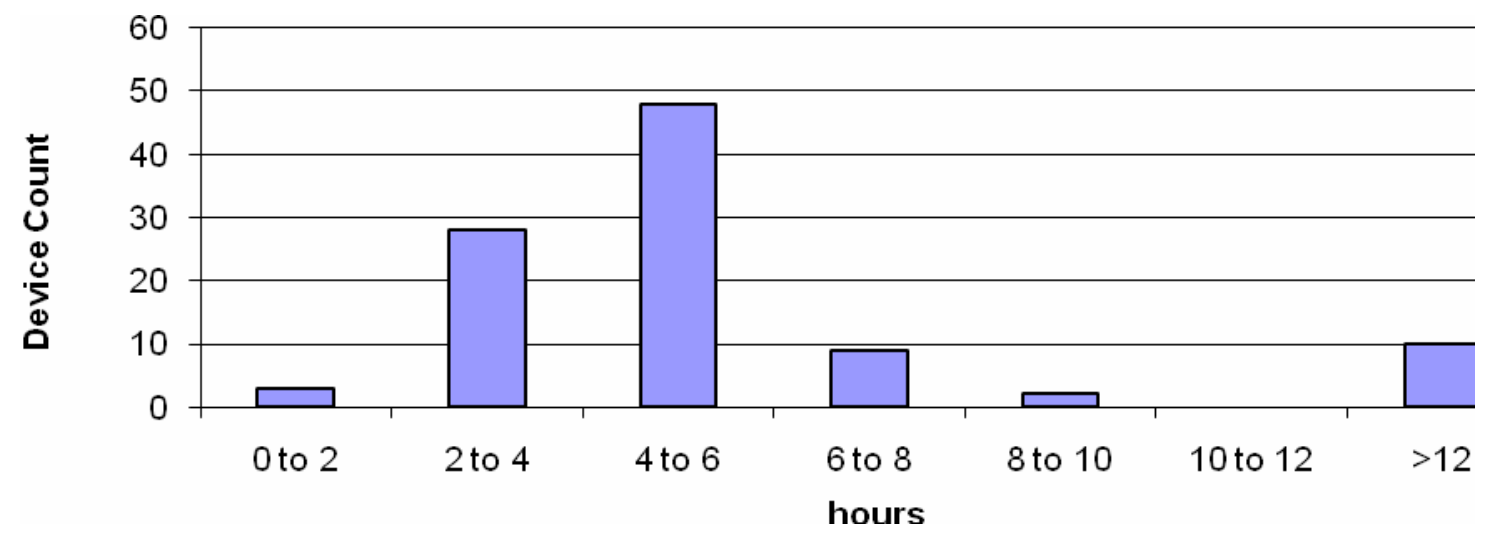

Figure 2.6 Average Unaccounted for Time from Late Temperature Readings

When the time between readings was more than the one hour limit, the average extra time over the hour for most devices was between 2 and 6 hours, as shown in Figure 2.6.

The event-level analyses described below on the indoor temperature changes over the course of the PLP events exclude devices for which part of the duration of an event was unaccounted for due to a late reading. The temperature at either the start or the end of the event was unknown for these excluded devices, preventing a reliable temperature change from being computed.

Exclusion from analyses on one event did not mean exclusion from analyses on other events.

In addition to the unaccounted for time between some temperature readings as described above, there were two levels of resolution on the recorded temperatures. Prior to July $24^{\text {th }}, 2009$, temperatures were recorded in whole numbers of degrees Celsius. Starting July $24^{\text {th }}$ and continuing through the testing season, recorded temperatures are to the five ten-thousandths of a degree Celsius. The first ten of thirty test events occurred prior to this transition. It is not known how the rounding was done in the temperatures prior to July $24^{\text {th }}$. The temperature change analyses in Section 2.2 and 2.3 below are for the most part less than one degree. Because the unknown method of rounding prevented precise inference on the temperature changes, the first ten events were excluded from the analyses below.

\subsection{Indoor Temperature Changes During 2009 PLP Test Events}

Following the indoor temperature reading transmission reliability assessment, the increases in inside temperature between the start and end of the thirty events were compiled. Figure 2.7 and 2.8 give the observed counts of temperature increases between the starts and ends of the events by event duration and outside temperature. The event durations in the 2009 PLP were short enough that, even at the height of the summer in the Mojave Desert, the measured indoor temperatures did not increase more than a few degrees. The maximum measured increase was 5.4 degrees Fahrenheit, which occurred for one household during a twenty minute test when the outside temperature was recorded as 95 degrees. No other single increase was as much as four degrees across all the devices and tests. 


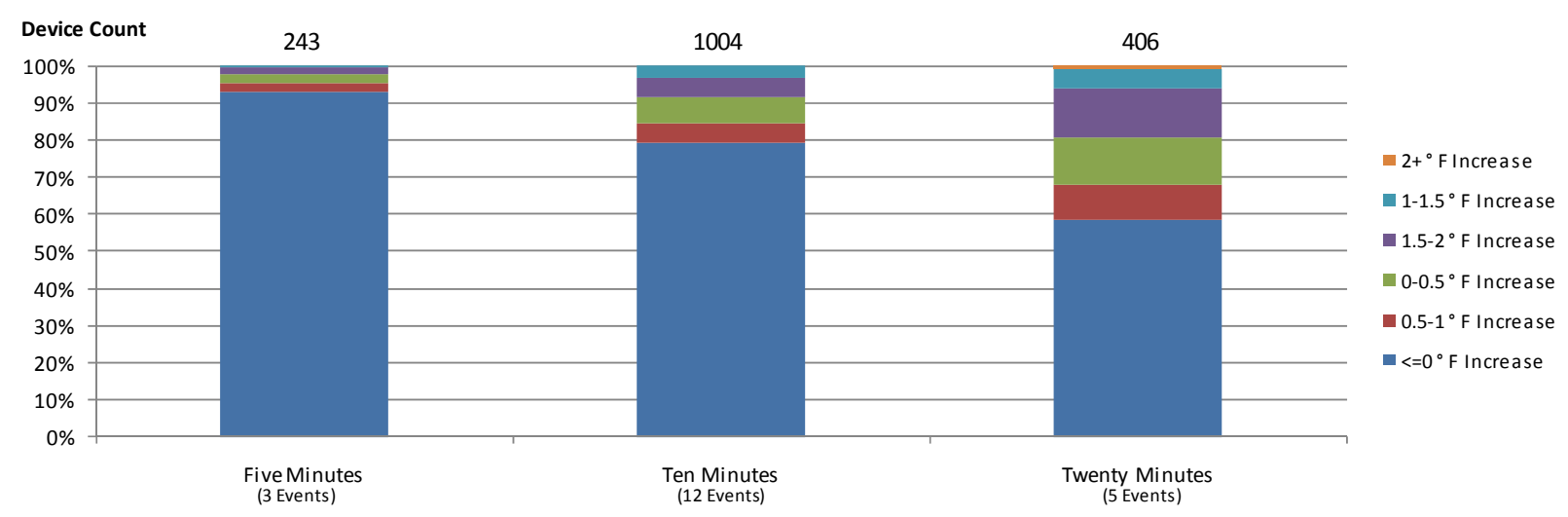

Figure 2.7 Count of indoor Temperature increases During Events by Event Durations Across All Events, Monitored Households

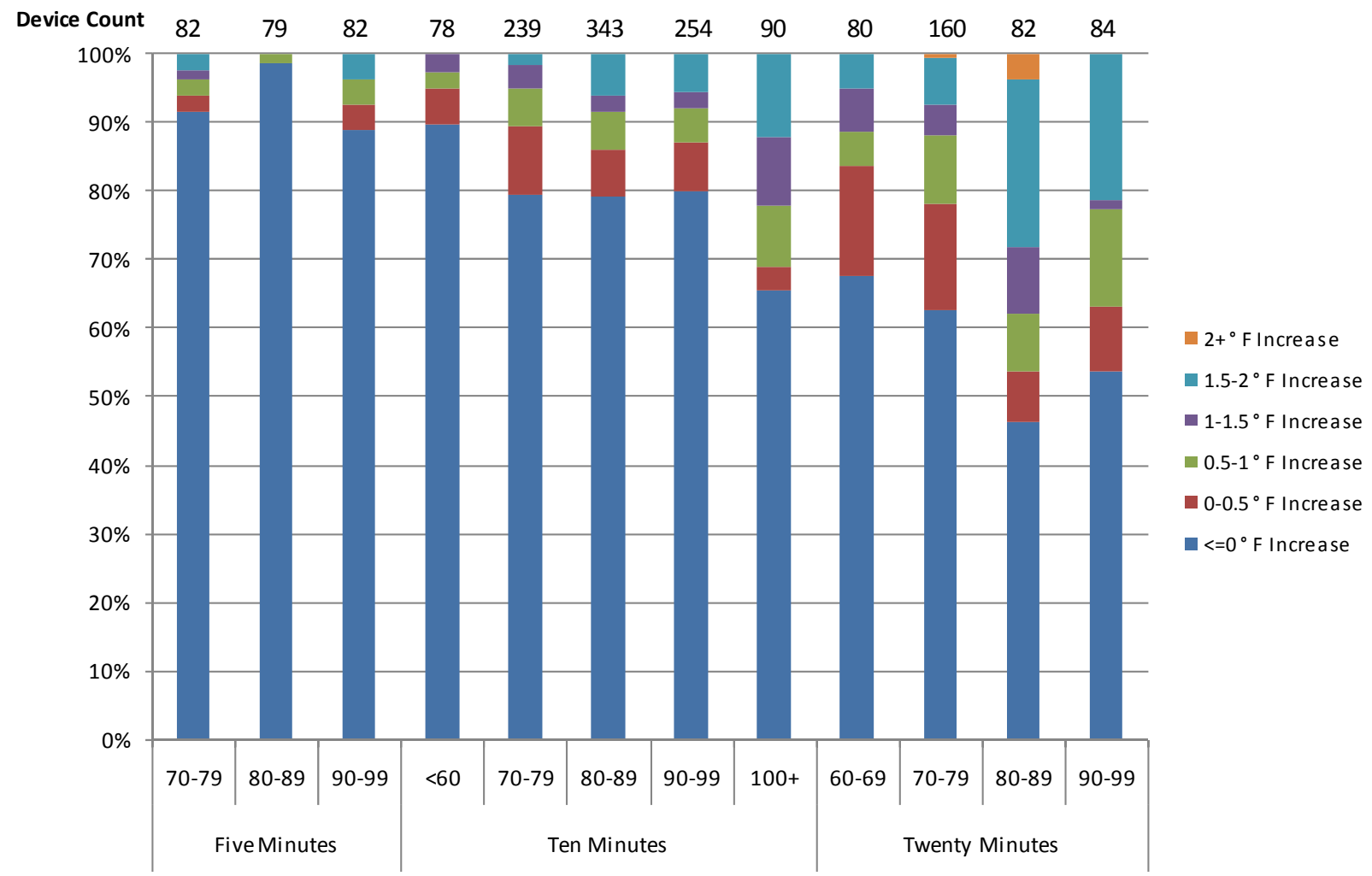

Figure 2.8 Count of indoor temperature increases during events by event durations and outside temperature across all events, monitored households

In general, as can be seen in both Figure 2.7 and 2.8, the longer the event and the greater the outside temperature, the more households had an inside temperature increase over the event, but even for the longest events and on the hottest days, most households had no change in indoor temperature between the start and end of the event. 


\subsection{Regression of Indoor Temperature Increases on Event Duration, Outside Temperature}

A fixed effects linear regression model of the indoor temperature increases from the starts to the ends of the $\mathrm{A} / \mathrm{C}$ curtailment events was fit on the duration and outside temperature associated with each event. A fixed effects model was chosen so that the parameter estimates associated with event duration and outside temperature were not clouded with the tendencies of certain homes to heat up more than others with the A/C cycled off.

\begin{tabular}{|l|r|r|}
\hline Value & \# & Percent \\
\hline Non-Zero/One & 366 & $22 \%$ \\
\hline One & 85 & $5 \%$ \\
\hline Zero & 1202 & $73 \%$ \\
\hline
\end{tabular}

Table 2.2 Count of the occurrences of zero and one degree temperature increases removed from the regression fit

As is shown in Table 2.2, almost three-quarters of the temperature changes from the devices across all events were zero. From Figure 2.8 it can be seen that most of the measured increases were zero for all duration/outside temperature subgroups of the test events. This cluster of points is highly influential on the fit of a linear regression. While the regression may be the best fit for the overall set of points, it does not fit particulary well to either the clump of zero increases or the non-zero increases. Because of this effect the concentration of zeros has on the regression, they were removed from the set of observations used in the model.

In addition to the zero values, there was a noticable cluster of events with a recorded temperature change of 1.8 degree Fahrenheit (1 degree Celcius). As can be seen in Table 2.2, this happened with far less frequency than the zero degree increases but they were still highly influential. In order to prevent any influence of the clustering on the regression, these events were also removed from the set of observations used in the model.

\begin{tabular}{|l|r|r|r|}
\hline Predictor Variable & Parameter Estimate & Standard Error & P-value \\
\hline Event Duration (minutes) & 0.0332 & 0.0094 & 0.0005 \\
\hline Outside Temperature (F) & 0.0068 & 0.0040 & .0939 \\
\hline
\end{tabular}

Table 2.3 Regression Parameter Estimates and Associated Levels of Precision

The parameter estimates and their associated standard errors given in Table 2.3 indicate a positive correlation between indoor temperature change and both the event duration and outside temperature. The larger parameter estimate and smaller p-value for event duration suggests that a one minute increase in event duration will have a bigger effect on the indoor temperature than will a one degree Fahrenheit increase in outside temperature, under the corresponding duration and outside temperature ranges observed in the 2009 PLP. 


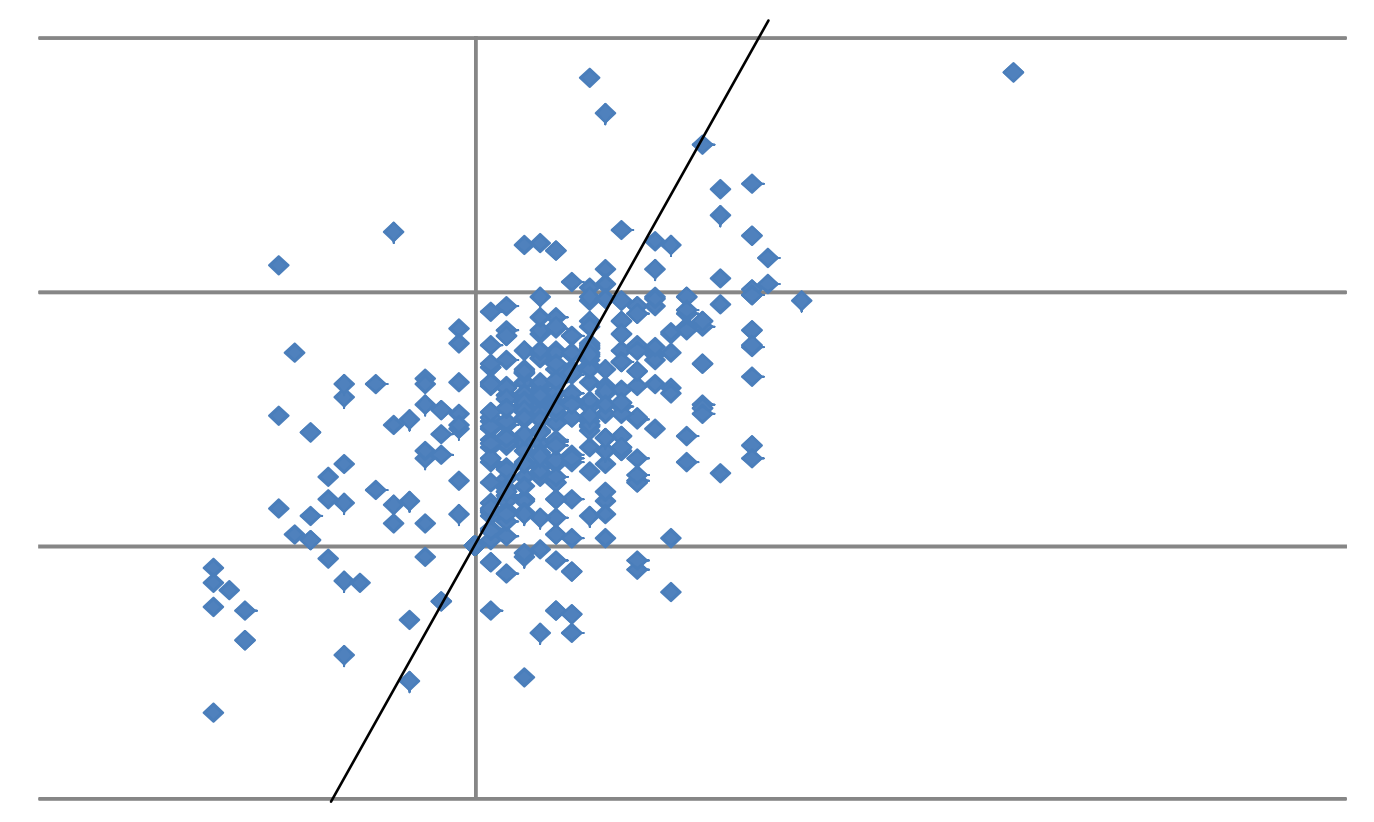

Figure 2.9 Predicted Indoor Temperature Increase by Actual Temperature Increase (Zero and one degree increases removed).

The temperature increases predicted by the fixed effects regression model and the actual increases have an approximately linear relationship, as can be seen in Figure 2.9. Had the model fit to the data been perfect, all points would lie on a straight line in the Figure above. The significant variability around the line representing a perfect fit suggests that for deeper insight into the relationship the indoor temperature increases have with the outside temperature and event duration beyond them being positively correlated, other classes of models should be considered.

\subsection{Logistic Regression of Indoor Temperature Increases on Event Duration, Outside Temperature}

A conditional logistic regression model was fit to estimate the probability of a temperature increase greater or equal to one degree Fahrenheit based on the time interval of the test and the outdoor temperature during the test period. The conditional logistic regression, much like a linear fixed-effects model, controls for unobserved variations across sites that potentially correlate with the independent variables. Unlike the ordinary least squares regression model, the conditional logistic can take heavy concentrations at certain values ( 0 and 1.8 in this case) since all values are recoded to 0 if the increase is less than 1 degree Fahrenheit or 1 if the increase is more than 1 degree. The functional form for the regression is as follows:

$$
L(\theta)=\frac{e^{y_{h i} x_{h i} \theta}}{1+e^{x_{h i} \theta}}
$$

Equation 2.1 Conditional Likelihood Function 
Where $y_{h i}$ is the fixed-effect ordered value ( 1 or 0$),{ }_{h i}$ is the index of $p$ covariates, and $\theta$ is the parameter vector.

\begin{tabular}{|l|r|r|c|}
\hline Predictor Variable & Parameter Estimate & Standard Error & P-value \\
\hline Event Duration (minutes) & 0.1814 & 0.0197 & $<.0001$ \\
\hline Outside Temperature (F) & 0.0478 & 0.0091 & $<.0001$ \\
\hline
\end{tabular}

Table 2.4 Logistic Regression Parameter Estimates and Associated Levels of Precision

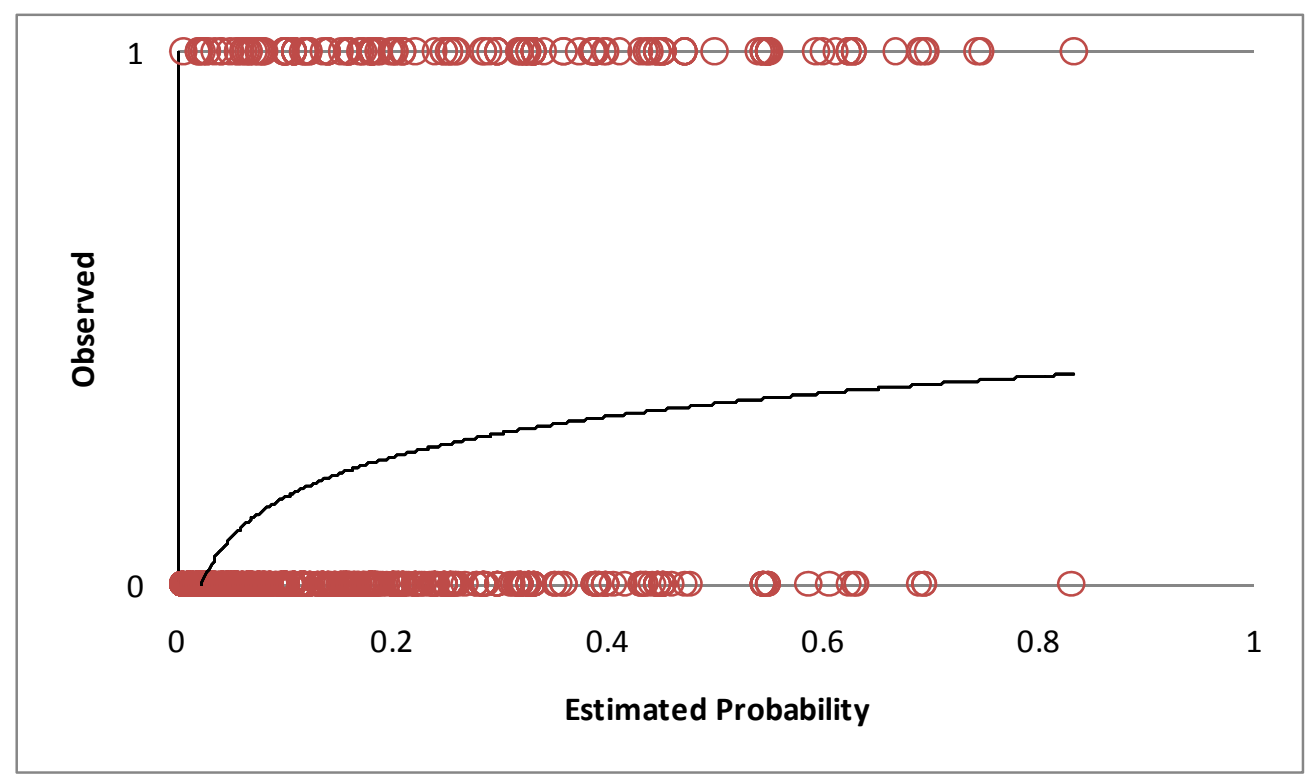

Figure 2.10 Temperature difference indicator by estimated probability of increase with fitted $\log$ of estimated probability.

The logistic model was not able to separate the observations perfectly into "successes" and "failures" but there was a higher fitted chance of temperature increase for the group that did increase.

\section{Household Impact Surveys}

KEMA and SCE developed two surveys to assess the PLP program awareness at Ft. Irwin - one for base residents and one for base leadership in the department of public works and building management.

\subsection{Leadership Survey}

The first survey was targeted at base leadership, such as building and facility managers. These surveys asked the leadership several questions:

1. Their job role or base responsibilities,

2. Which residential communities had buildings they were responsible for, 
3. How many complaints they received about air conditioning performance this summer, and

4. Whether the number of complaints was different this summer versus last summer.

The leadership survey was programmed for online administration by Survey Monkey. A link to the survey was emailed to 17 people. Three responded for a completion rate of 18 percent. With only three responses, KEMA did not subject these data to statistical analysis. A summary of the results follows.

Two of the respondents indicated base-wide responsibilities. The third respondent indicated responsibility for an administrative building. None of the respondents indicated responsibility for buildings in any of the residential communities on base.

None of the respondents reported receiving complaints from residential tenants about building comfort or air conditioning performance. When asked to compare the number of complaints to the previous summer, one of the respondents said it was lower in the summer of 2009.

None of the respondents reported receiving complaints from non-residential tenants about building comfort or air conditioning performance. When asked to compare the number of complaints to the previous summer, one of the respondents said it was lower in the summer of 2009.

\subsection{Residential Survey}

The second survey was targeted at base residents. It was intended to gather the following information:

1. Demographic information,

2. Typical summer air conditioner use, and

3. Awareness of curtailment events that occurred this summer.

The residential survey was mailed to 110 people and we received 16 responses for a response rate of 14.5 percent.

\subsubsection{Demographics}

About half of the respondents live in the same one of the several neighborhoods on the base. Half have lived in the same residence since at least last summer (2008). Most households have at two adults (age 18 -59) and half have at least one child aged 0 to 5 . Most households reported someone is home at least four weekdays per week.

Ninety-four percent of the respondents reported living at the same residence since June 1, 2009. Fifty-six percent of the respondents reported living in Fort Irwin during the summer of 2008.

About half of the respondents have at least one child aged 0 to 5 years old. One fourth have at least one child aged 6 to 17. One hundred percent of the households had at least one 18 to 59 year old, and 87 percent had two. None of the households had anyone aged 60 or older. 
It was very common for someone to be at home during the weekdays. Eighty-one percent of the respondents said someone was home four or more days per week. About half of these respondents have children aged 0 to 5 years old.

\begin{tabular}{|l|r|r|}
\hline $\begin{array}{l}\text { This summer, how many weekdays per } \\
\text { week was someone at home during the } \\
\text { day? }\end{array}$ & N & Percent \\
\hline $\mathbf{0}$ & 2 & $12 \%$ \\
\hline $\mathbf{1}$ & 1 & $6 \%$ \\
\hline $\mathbf{4}$ & 1 & $6 \%$ \\
\hline $\mathbf{5}$ & 12 & $75 \%$ \\
\hline Total & 16 & $100 \%$ \\
\hline
\end{tabular}

Table 3.1 Weekdays When Someone Is Home

\subsubsection{Typical Summer Air Conditioner Use}

The typical respondent used their air conditioner every day and set it manually. Respondents who manually set their thermostats turned them on when the outside temperature got above 86 degrees. When someone was home, respondents set the thermostat to over 70 degrees. When nobody was home, they turned the air conditioner off or set the thermostat above 75 degrees. At night time, they set their thermostats in the 70s. Other than using the air conditioner, most respondents keep cool by turning on fans, closing the blinds/curtains, and changing into cooler clothes.

Half of the respondents said they used their air conditioner every day. One-fourth said they used it only on the hottest days. One-eighth used it often but not every day and the other eighth did not answer.

\begin{tabular}{|l|r|r|}
\hline $\begin{array}{l}\text { Which of the following statements best describes the } \\
\text { way your household used the air conditioner this } \\
\text { summer? }\end{array}$ & N & Percent \\
\hline We used it every day & 8 & $50 \%$ \\
\hline We used it only on the hottest days & 4 & $25 \%$ \\
\hline We used it often, but not every day & 2 & $12 \%$ \\
\hline No answer & 2 & $12 \%$ \\
\hline Total & 16 & $100 \%$ \\
\hline
\end{tabular}

Table 3.2 Air Conditioner Usage 
Almost two-thirds of the respondents reported manually setting their thermostats. Only onefourth indicated that they program their thermostats.

\begin{tabular}{|l|r|r|}
\hline $\begin{array}{l}\text { How you primarily utilize your thermostat (cool } \\
\text { setting) in the summer? }\end{array}$ & N & Percent \\
\hline Manual & 10 & $62 \%$ \\
\hline Programmed & 4 & $25 \%$ \\
\hline No answer & 1 & $6 \%$ \\
\hline Not Applicable & 1 & $6 \%$ \\
\hline Total & 16 & $100 \%$ \\
\hline
\end{tabular}

Table 3.3 Thermostat Usage

Seven of the ten respondents who set their thermostat manually reported turning it on when the outside temperature was 86 or higher.

\begin{tabular}{|l|r|r|}
\hline Outside air temp when AC turned on & \multicolumn{1}{|c|}{ N } & Percent \\
\hline $\mathbf{6 6 - 7 0}$ & 1 & $10 \%$ \\
\hline $\mathbf{8 1 - 8 5}$ & 1 & $10 \%$ \\
\hline $\mathbf{8 6 - 9 0}$ & 3 & $30 \%$ \\
\hline $\mathbf{9 1 - 9 5}$ & 2 & $20 \%$ \\
\hline Over 95 & 2 & $20 \%$ \\
\hline No Answer & 1 & $10 \%$ \\
\hline Total & 10 & $100 \%$ \\
\hline
\end{tabular}

Table 3.4 Outside Temperature Inducing Air Conditioning 
The survey asked respondents what temperature they set their thermostats to during different times of day. During the daytime when someone was home, one-fourth of the respondents said they set their thermostat at 70 or less. Another one-fourth reported setting their thermostats between 71 and 75, and another one-fourth reported setting them between 76 and 80 . Only six percent reported a thermostat setting above 80 degrees Fahrenheit.

\begin{tabular}{|l|r|r|}
\hline $\begin{array}{l}\text { On weekdays this summer, what temperature did you } \\
\text { usually set your thermostat to during the following times? } \\
\text { During the day when someone was home? - Degrees F }\end{array}$ & N & Percent \\
\hline Less than 66 & 1 & $6 \%$ \\
\hline $\mathbf{6 6 - 7 0}$ & 3 & $18 \%$ \\
\hline $\mathbf{7 1 - 7 5}$ & 4 & $25 \%$ \\
\hline $\mathbf{7 6 - 8 0}$ & 4 & $25 \%$ \\
\hline $\mathbf{8 1 - 8 5}$ & 1 & $6 \%$ \\
\hline No Answer & 2 & $12 \%$ \\
\hline Not Applicable & 1 & $6 \%$ \\
\hline Total & 16 & $100 \%$ \\
\hline
\end{tabular}

Table 3.5 Thermostat Setting When Home 
The survey also asked respondents what temperature they set their thermostats to on weekdays when nobody is home. These responses showed a different pattern than when someone was home. Over half of the respondents said they turn their air conditioner off or set their thermostats at 76 degrees or higher. About one-fifth of the respondents said they set their thermostat at 75 degrees or less.

\begin{tabular}{|l|r|r|}
\hline $\begin{array}{l}\text { On weekdays this summer, what temperature did you usually } \\
\text { set your thermostat to during the following times? During the } \\
\text { day when nobody was home? - Degrees F }\end{array}$ & N & Percent \\
\hline Less than 66 & 1 & $6 \%$ \\
\hline $\mathbf{6 6 - 7 0}$ & 1 & $6 \%$ \\
\hline $\mathbf{7 1 - 7 5}$ & 1 & $6 \%$ \\
\hline $\mathbf{7 6 - 8 0}$ & 6 & $37 \%$ \\
\hline $\mathbf{8 1 - 8 5}$ & 1 & $6 \%$ \\
\hline Off & 2 & $12 \%$ \\
\hline No Answer & 3 & $18 \%$ \\
\hline Not Applicable & 1 & $6 \%$ \\
\hline Total & 16 & $100 \%$ \\
\hline
\end{tabular}

Table 3.6 Thermostat Setting When Gone

On weekday nights, respondents tend to keep their thermostats in the 70's. Respondents do not seem to be returning home at the end of the day and "cranking" the AC. Typical seasonal nighttime lows in Fort Irwin range from 65 to 75 degrees, so these thermostat settings could represent setting the thermostat to a temperature close to the nighttime low.

\begin{tabular}{|l|r|r|}
\hline $\begin{array}{l}\text { On weekdays this summer, what temperature did you } \\
\text { usually set your thermostat to during the following } \\
\text { times? At night during sleeping hours? - Degrees F }\end{array}$ & $\mathbf{N}$ & Percent \\
\hline Less than 66 & 1 & $6 \%$ \\
\hline $\mathbf{6 6 - 7 0}$ & 1 & $6 \%$ \\
\hline $\mathbf{7 1 - 7 5}$ & 7 & $43 \%$ \\
\hline $\mathbf{7 6 - 8 0}$ & 2 & $12 \%$ \\
\hline $\mathbf{8 1 - 8 5}$ & 1 & $6 \%$ \\
\hline
\end{tabular}




\begin{tabular}{|l|r|r|}
\hline $\begin{array}{l}\text { On weekdays this summer, what temperature did you } \\
\text { usually set your thermostat to during the following } \\
\text { times? At night during sleeping hours? - Degrees F }\end{array}$ & N & Percent \\
\hline Off & 1 & $6 \%$ \\
\hline No Answer & 3 & $18 \%$ \\
\hline Total & 16 & $100 \%$ \\
\hline
\end{tabular}

Table 3.7 Thermostat Setting During Sleeping Hours

About half (56\%) of the respondents said that their air conditioner reliably cooled their home on the hottest days in the summer.

The survey asked respondents what they do to keep cool other than using their air conditioner. Almost all reported using ceiling or portable fans (93\%) and closing the blinds or curtains (87\%). More than two-thirds said they change into different clothing. Less than half said they closed off unoccupied rooms (43\%), avoided doing things that generate heat (31\%), lower their thermostat setting (31\%), or go to a cooler location like the pool or movies (18\%). No respondent reported setting the thermostat to a higher temperature.

\begin{tabular}{|l|r|r|}
\hline $\begin{array}{l}\text { Other than Air Conditioning, which of the following actions, if } \\
\text { any, do you take to help keep cool? }\end{array}$ & N & Percent \\
\hline Turn on ceiling fans and/or portable fans & 15 & $93 \%$ \\
\hline Close the blinds/curtains to keep the sun out & 14 & $87 \%$ \\
\hline Change into different clothing to keep cool & 11 & $68 \%$ \\
\hline Close off unoccupied rooms & 7 & $43 \%$ \\
\hline Avoid doing things that generate heat (cooking, hot showers) & 5 & $31 \%$ \\
\hline Set the thermostat to a lower temperature & 3 & $31 \%$ \\
\hline Go to a cooler location like the pool, movies or store & 0 & $18 \%$ \\
\hline Set the thermostat to a higher temperature & 1 & $6 \%$ \\
\hline No answer
\end{tabular}

Table 3.8 Other Cooling Action

\subsubsection{Awareness of Summer Curtailment Events}

Awareness of the summer curtailment events was very low. Seventy five percent of the respondents said that they did not notice the events and that the events did not affect their comfort. Of the three respondents who said they noticed the events, one of them said they 
noticed the events during the weekend. Events did not occur during the weekend, so this respondent's perception of events occurring would not reflect an actual event taking place and may indicate other air conditioning system issues. Comfort was not affected by the tests. Most respondents did nothing in response to the events.

Nine respondents said they lived in Fort Irwin in the summer of 2008. Of those nine respondents, only one said that they noticed a difference in their air conditioning performance between 2008 and 2009.

\begin{tabular}{|l|r|r|}
\hline $\begin{array}{l}\text { Did you notice any differences in the performance of your } \\
\text { air conditioning system this summer (2009) versus last } \\
\text { summer (2008)? }\end{array}$ & N & Percent \\
\hline No & 6 & $66 \%$ \\
\hline Yes & 1 & $11 \%$ \\
\hline Not Applicable & 2 & $22 \%$ \\
\hline Total & 9 & $100 \%$ \\
\hline
\end{tabular}

Table 3.9 Performance Differences Versus Last Summer

Using a 0 to 5 point scale, three-fourths of the respondents said they did not notice the testing and gave a rating of 0 on the scale. Twelve percent of the respondents gave an answer above the midpoint of the scale.

\begin{tabular}{|l|r|r|}
\hline $\begin{array}{l}\text { If you noticed the Air Conditioning tests, at } \\
\text { what time did you notice? Did not notice testing }\end{array}$ & N & Percent \\
\hline Did not notice testing & 12 & $75 \%$ \\
\hline Afternoon & 1 & $6 \%$ \\
\hline Morning & 1 & $6 \%$ \\
\hline Weekend & 1 & $6 \%$ \\
\hline No answer & 1 & $6 \%$ \\
\hline Total & 16 & $100 \%$ \\
\hline
\end{tabular}

Table 3.10 Time When Tests Were Noticed 


\begin{tabular}{|l|r|r|}
\hline $\begin{array}{l}\text { Did you notice Air Conditioning tests being } \\
\text { conducted this summer? (Rate 0-5 with 0 } \\
\text { being hardly noticed and } 5 \text { being noticed a } \\
\text { great deal) }\end{array}$ & N & Percent \\
\hline $\mathbf{0}$ & 12 & $75 \%$ \\
\hline $\mathbf{2}$ & 1 & $6 \%$ \\
\hline $\mathbf{3}^{\mathbf{4}}$ & 1 & $6 \%$ \\
\hline $\mathbf{5}$ & 1 & $6 \%$ \\
\hline No answer & 1 & $6 \%$ \\
\hline Total & 16 & $100 \%$ \\
\hline
\end{tabular}

Table 3.11 How Noticeable Tests Were

Most of the respondents did not notice the testing, and they also said that the testing did not affect their comfort level. Only one respondent said that the testing affected their comfort level at all, and they gave an answer of 1 on a 0 to 5 point scale.

\begin{tabular}{|l|r|r|}
\hline $\begin{array}{l}\text { Did the air conditioning testing affect your comfort } \\
\text { level? (Rate 0-5 with 0 being no effect on comfort } \\
\text { and } 5 \text { being significant impact on comfort) }\end{array}$ & N & Percent \\
\hline $\mathbf{0}$ & 12 & $75 \%$ \\
\hline $\mathbf{1}$ & 1 & $6 \%$ \\
\hline No answer & 3 & $18 \%$ \\
\hline Total & 16 & $100 \%$ \\
\hline
\end{tabular}

Table 3.12 Affect Tests Had On Comfort Level

\footnotetext{
${ }^{4}$ Respondent indicated that they noticed the testing during the weekends, although no testing was conducted on weekends.
} 
Most respondents (80\%) did nothing in response to the events. This makes sense if most of them did not notice the events to begin with. Only 12 percent contacted base facilities maintenance to report a problem. None of the respondents turned on their air conditioners for longer than they normally would after the event was over.

\begin{tabular}{|c|c|c|}
\hline $\begin{array}{l}\text { Other than Air Conditioning, which of the following actions, } \\
\text { if any, do you take in response to the airconditioning } \\
\text { testing? }\end{array}$ & $\mathbf{N}$ & Percent \\
\hline Nothing - We have not done anything in response & 7 & $43 \%$ \\
\hline Closed the blinds/curtains to keep the sun out & 4 & $25 \%$ \\
\hline Turned on ceiling fans and/or portable fans & 3 & $18 \%$ \\
\hline Closed off unoccupied rooms & 3 & $18 \%$ \\
\hline Changed into different clothing to keep cool & 3 & $18 \%$ \\
\hline $\begin{array}{l}\text { Checked your AC equipment to make sure it was not } \\
\text { broken / malfunctioning }\end{array}$ & 2 & $12 \%$ \\
\hline $\begin{array}{l}\text { Contacted base facilities customer service number to report } \\
\text { a problem }\end{array}$ & 2 & $12 \%$ \\
\hline Went to a cooler location like the pool, movies or store & 2 & $12 \%$ \\
\hline $\begin{array}{l}\text { Avoided doing things that generate heat (cooking, hot } \\
\text { showers) }\end{array}$ & 1 & $6 \%$ \\
\hline $\begin{array}{l}\text { Turned on your AC for longer than you normally would } \\
\text { have after the event to cool down }\end{array}$ & 0 & $0 \%$ \\
\hline Don't know & 2 & $12 \%$ \\
\hline No answer & 4 & $25 \%$ \\
\hline
\end{tabular}

Table 3.13 Response to Testing

\section{Conclusions}

The results of both phases of this investigation suggest that there was very minimal or negligible impact of the Participating Load Pilot test events on participating residents. Even in the height of summer in the desert with temperatures in excess of $100^{\circ} \mathrm{F}$, homes did not heat up more than a few degrees in the five, ten, or twenty minutes with the air conditioning cycled off. The vast majority of residents, the survey suggests, did not even notice the events at all during the summer and no one found them to be an even moderate disruption to their comfort. 
The results of this study suggest that the impacts on comfort from short-duration interruptions of air-conditioners, even in very hot climates, are for the most part very modest, if they are even noticed at all. Ft Irwin has been active in upgrading their facilities for Energy Efficiency and building insulation and energy efficient windows would contribute to a building being able to sustain a level of comfort for occupants during short-duration interruptions of air-conditioners. Still, we should expect that these impacts will increase with longer interruptions of airconditioning. By the same token, we should also expect that they will be less significant in cooler climates. 